DOI: $10.1590 / 1089-6891 v 16 i 127798$

PRODUÇÃO ANIMAL

\title{
RECEITA INDUSTRIAL DE CORTES SECUNDÁRIOS DA CARCAÇA DE BOVINOS MESTIÇOS LEITEIROS, NÃO CASTRADOS OU SUBMETIDOS A DIFERENTES FORMAS DE CASTRAÇÃO
}

\author{
INDUSTRIAL INCOME WITH DEBONED CUTS SALES OF DAIRY \\ CROSSBRED MALES, NON-CASTRATED OR SUBMITED TO DIFFERENT \\ CASTRATION METHODS
}

Fabiano Nunes Vaz ${ }^{1}$

João Restle ${ }^{2}$

João Teodoro Pádua ${ }^{3}$

Danielle Curado de Santana Morales ${ }^{4}$

Paulo Santana Pacheco ${ }^{1}$

Cristiano Sales Prado ${ }^{2}$

1 Professor Doutor da Universidade Federal de Santa Maria, Santa Maria, RS, Brasil fabianonunesvaz@gmail.com

2 Professor PhD da Universidade Federal de Tocantins, Araguaína, TO, Brasil.

3 Professores Doutores da Universidade Federal de Goiás, Goiânia, GO, Brasil.

4 Zootecnista, Mestre pela Universidade Federal de Goiás, Goiânia, GO, Brasil

\section{Resumo:}

O objetivo deste trabalho foi realizar a análise dos rendimentos e das receitas com a venda de cortes desossados da carcaça de 84 bovinos mestiços Holandês x Zebu, não castrados ou submetidos a diferentes métodos de castração aos doze meses. Os animais foram distribuídos aleatoriamente em quatro tratamentos, com 21 repetições por tratamento: machos castrados com burdizzo, castrados por meio da remoção do ápice do escroto, castrados com incisões laterais no escroto e animais não castrados. $\mathrm{Na}$ análise dos cortes primários da carcaça, foi observado maior rendimento do corte dianteiro dos não castrados e menor rendimento de ponta de agulha destes em relação aos castrados. Observou-se que os animais não castrados apresentaram maiores pesos e rendimentos dos cortes desossados lagarto e acém do que os castrados. A análise das receitas industriais com a venda dos cortes primários mostrou que a receita dos animais castrados por remoção do tampão foi 13,3\% inferior aos não castrados. No entanto, na análise das receitas oriundas da venda dos cortes desossados, observou-se que a menor receita foi dos castrados por incisão lateral em relação aos machos não castrados $(-9,9 \%)$. 
Palavras-Chave: análise econômica; castração com burdizzo; desossa; machos não castrados; raça Holandesa.

\begin{abstract}
:
The objective of this study was to assess the income and revenues from the sale of boneless cuts of the carcass of 84 Holstein $\mathrm{x}$ Zebu crossbred males, non-castrated or submitted to different castration methods at twelve month of age. The animals were randomly divided into four treatments with 21 replications each: castrated with burdizzo, castrated by removing the scrotum apex, castrated with lateral incisions in the scrotum and non-castrated. The slaughter of animals occurred on the same date, at 30 months of age. Carcass primary cuts analysis showed higher forequarter yield in the non-castrated and lower rib cut yield in relation to the castrated animals. Non-castrated animals showed higher weights and yields of deboned chuck and eye round cuts than the castrated animals. Industrial sale revenue of primary cuts analysis showed that the animals castrated by removing scrotum apex were $13.3 \%$ less profitable than non-castrated males. However, sale revenues of boneless cuts analysis showed that the lowest revenue income was from animals castrated by lateral incision in relation to non-castrated males (-9.9\%).
\end{abstract}

Keywords: burdizzo castration; deboned; economical analysis; Holstein; non-castrated males; slaughterhouse.

Recebido em: 26 dez. de 2013.

Aceito em:11 set. 2014.

\title{
Introdução
}

A produção de carne de machos de origem leiteira ainda é baixa no Brasil, quando comparado a outros países. Parte dos bezerros são abatidos após o nascimento, ou são criados em condições de alimentação deficientes causando elevada mortalidade ou retardando o desenvolvimento corporal, com resultados negativos sobre as características de carcaça e da carne.

Visando aumentar a produção de carne de machos de origem leiteira, é de fundamental importância melhorar as condições alimentares. Além disso, é necessário avaliar os reflexos de questões básicas de manejo, entre elas a opção em castrar ou não os machos. Do ponto de vista da produção, a pesquisa demonstrou que animais não castrados são mais eficientes quanto ao ganho em peso quando comparados aos $\operatorname{castrados}^{(1)}$. No entanto, podem-se citar duas desvantagens da manutenção de animais não castrados destinados ao abate: a primeira seria a dificuldade de manejo, principalmente em animais confinados, tornando-se menos dóceis e com montas frequentes, influenciando na qualidade da carne. A segunda seria o maior tempo para os animais atingirem adequado acabamento da carcaça ${ }^{(2-6)}$. Já do ponto de vista da indústria frigorífica, existe estímulo à castração, em função do melhor acabamento de carcaça e ao maior desenvolvimento relativo do quarto traseiro ${ }^{(5,7)}$, onde se situam os cortes mais valorizados da carcaça. Ao mesmo tempo, a indústria reconhece a melhor conformação de carcaça dos animais não castrados ${ }^{(7)}$. 
O melhor método de castração, ainda é discutido nos diferentes criatórios, buscando-se reduzir a perda econômica originária do estresse da castração e atender aos preceitos de bem-estar animal ${ }^{(8-10)}$. Os métodos cirúrgicos hoje recomendados são a remoção do "tampão", no qual os testículos são removidos por meio da extirpação do ápice da bolsa escrotal, e a incisão lateral, no qual os testículos são exteriorizados e depois removidos por meio de incisões feitas lateralmente à bolsa escrotal. Já a castração com o uso de burdizzo consiste em esmagar o cordão espermático sem abrir o escroto ${ }^{(11)}$.

Em seu estudo, Pascoal et al. ${ }^{(12)}$ demonstraram que a análise econômica direcionada à indústria frigorífica deve levar em consideração o rendimento industrial dos cortes desossados de uma carcaça, pois os valores obtidos transcendem o simples entendimento sobre conformação e acabamento de carcaça. Isso porque a agregação de valor para toda a cadeia produtiva passa pelo processamento dos cortes da carcaça, que hoje precisam ser comercializados na forma de cortes secundários, tanto para o mercado externo como para o mercado interno. Este trabalho teve como objetivo realizar a análise dos rendimentos e das receitas com a venda de cortes desossados da carcaça de machos mestiços leiteiros não castrados ou submetidos a diferentes métodos de castração.

\section{Material e Métodos}

Foram usados 84 bovinos contemporâneos, mestiços oriundos do cruzamento de raças de origem europeia com raças zebuínas, com predominância das raças Holandês e Gir, com peso médio inicial de $176,1 \pm 1,4 \mathrm{~kg}$, com idade inicial de 12 meses, provenientes de criatórios particulares localizados no estado de Goiás. O experimento foi conduzido nos anos de 2001 a 2002.

No início do experimento, todos os animais foram vermifugados e vacinados contra clostridioses e febre aftosa, obedecendo às recomendações sanitárias do órgão estadual regulador. Durante o crescimento dos animais, a campo, o combate ao carrapato ocorreu conforme a infestação observada.

Os 84 animais foram aleatoriamente divididos em quatro grupos com 21 repetições: i) animais castrados com burdizzo; ii) animais castrados cirurgicamente por meio da remoção do ápice da bolsa escrotal ("tampão"); iii) animais castrados cirurgicamente por meio de incisões laterais; e iv) animais controle, os quais não foram castrados.

Para realizar a castração com burdizzo, foi feito o esmagamento do cordão espermático sem abrir o escroto. No método cirúrgico tampão, o segmento distal do escroto sofreu incisão transversal para expor as glândulas, realizando-se em seguida a secção dos cordões espermáticos com o uso de emasculador. Já para a castração com incisões laterais, foi feita a incisão longitudinal de 5 a $10 \mathrm{~cm}$ na pele e túnica vaginal e depois de seccionado o ligamento inguino-testicular, a 1 ou 2 dedos abaixo da ligadura, se emasculou e se tracionou o testículo, repetindo-se a operação no lado oposto.

Os animais foram mantidos nas mesmas condições em pastagem de Brachiaria brizantha, com lotação média de duas cabeças/ha, providos de bebedouros e cochos para fornecimento da suplementação mineral e proteica. Ao atingirem peso médio de $400 \mathrm{~kg}$, aos 30 meses de idade, os animais foram enviados para serem abatidos em frigorífico comercial, com Serviço de Inspeção Federal (SIF), local que atende à regulamentação de abate humanitário e bem estar animal. Para o abate, os animais foram 
insensibilizados com pistola pneumática, seguindo o procedimento de sangria, conforme normas do SIF.

Após o abate e evisceração, as carcaças foram divididas longitudinalmente ao meio, pesadas e identificadas com etiquetas plásticas, com número sequencial de entrada do box de atordoamento, amarradas no braço de cada meia carcaça.

Após permanência de 18 horas em câmara fria, foram tomados os pesos da carcaça fria e, depois do seccionamento dos cortes primários, foram pesados os traseiros especiais, os dianteiros e as pontas de agulha. Na sequência ocorreu a desossa, resultando em 21 cortes secundários mais os recortes, além do sebo e dos ossos.

Os dados coletados relativos aos cortes primários e secundários da carcaça foram analisados pelo método dos quadrados mínimos para avaliar os efeitos dos procedimentos utilizados nos grupos de animais sobre as variáveis dependentes. Os dados foram analisados através do procedimento GLM do programa computacional SAS. Foi adotado o seguinte modelo matemático: $Y_{i j}=\mu+C_{i}+e_{i j}$, sendo $Y_{i j}$ : conjunto das variáveis dependentes; $\mu$ : média geral; $\mathrm{C}_{\mathrm{i}}$ : efeito do i-ésimo tipo de castração e condição sexual $(1,2,3,4)$; $\mathrm{e}_{\mathrm{ij}}$ : erro experimental, contendo os efeitos não controlados. As médias que mostraram diferença estatística entre si foram comparadas pelo teste de Tukey ao nível de $5 \%$ de significância.

Para análise de receitas e ponto de equilíbrio foram coletados dados relativos aos preços de venda de cortes primários e secundários, os quais foram multiplicados pelos pesos de cada corte, visando-se obter a receita total com a venda da meia carcaça e da carcaça inteira. Para obter o preço de equilíbrio para aquisição, foi dividida a receita da carcaça inteira pelo número de arrobas de carcaça.

Quando o trabalho de campo foi realizado, as instituições brasileiras não possuíam comitês de ética para julgar os projetos de pesquisa em relação aos procedimentos a serem usados. De qualquer forma, o manejo dos animais utilizados neste trabalho esteve de acordo com as recomendações técnicas de bemestar e respeito aos animais.

\section{Resultados e Discussão}

Na Tabela 1, observa-se que os animais castrados por meio da remoção do tampão da bolsa escrotal mostraram menor peso de traseiro especial que os demais $(\mathrm{P}<0,05)$. A diferença no peso do traseiro especial pode estar associada ao procedimento cirúrgico, por ser mais traumático, acarretando menor desenvolvimento dos animais. 
Tabela 1: Médias e erros-padrão para peso e percentagem dos cortes traseiro especial, dianteiro e ponta de agulha de mestiços de origem leiteira, não castrados ou submetidos a diferentes métodos de castração

\begin{tabular}{lcccc}
\hline \multirow{2}{*}{ Cortes primários } & \multicolumn{4}{c}{ Grupo analisado } \\
\cline { 2 - 5 } & $\begin{array}{c}\text { Não } \\
\text { castrado }\end{array}$ & $\begin{array}{c}\text { Uso de } \\
\text { burdizzo }\end{array}$ & $\begin{array}{c}\text { Incisão } \\
\text { lateral }\end{array}$ & $\begin{array}{c}\text { Remoção do } \\
\text { tampão }\end{array}$ \\
\hline Traseiro especial, kg & $100,4 \pm 2,7^{\mathrm{a}^{*}}$ & $96,8 \pm 2,7^{\mathrm{a}}$ & $97,8 \pm 2,8^{\mathrm{a}}$ & $88,6 \pm 3,0^{\mathrm{b}}$ \\
Traseiro especial, \% & $48,4 \pm 0,3$ & $49,0 \pm 0,3$ & $49,5 \pm 0,3$ & $49,4 \pm 0,4$ \\
Dianteiro, kg & $83,2 \pm 2,8^{\mathrm{a}}$ & $75,7 \pm 2,8^{\mathrm{ab}}$ & $74,7 \pm 2,8^{\mathrm{b}}$ & $68,5 \pm 3,0^{\mathrm{b}}$ \\
Dianteiro, \% & $39,8 \pm 0,3^{\mathrm{a}}$ & $38,1 \pm 0,3^{\mathrm{b}}$ & $37,7 \pm 0,3^{\mathrm{b}}$ & $38,0 \pm 0,3^{\mathrm{b}}$ \\
Ponta de agulha, kg & $24,4 \pm 0,9$ & $25,8 \pm 0,9$ & $25,5 \pm 1,0$ & $22,6 \pm 1,0$ \\
Ponta de agulha, \% & $11,7 \pm 0,2^{\mathrm{b}}$ & $12,9 \pm 0,2^{\mathrm{a}}$ & $12,8 \pm 0,2^{\mathrm{a}}$ & $12,6 \pm 0,3^{\mathrm{a}}$ \\
Total da carcaça, @ & 13,87 & 13,22 & 13,20 & 11,98 \\
\hline
\end{tabular}

* Médias na linha seguidas por letras diferentes diferem $(\mathrm{P}<0,05)$ pelo Teste de Tukey.

Segundo Restle et al. ${ }^{(13)}$ não foi observada diferença no desenvolvimento dos animais castrados à faca ou com burdizzo, durante o crescimento dos oito aos 25 meses de idade. No entanto, os autores não identificaram como foram feitas as incisões para a castração à faca. Pesquisando as complicações pósoperatórias de bovinos mestiços europeu x zebu, decorrentes da castração por meio da incisão lateral ou por meio da remoção do "tampão", Silva et al. ${ }^{(14)}$ não verificaram diferenças nas contagens de problemas decorrentes de hemorragias, miíases, granulomas, abcessos e funiculite entre as duas técnicas cirúrgicas.

A Tabela 1 mostra que, embora apresentassem menor peso de traseiro especial, não houve diferença significativa no rendimento do traseiro especial em relação ao peso de carcaça fria $(\mathrm{P}>0,05)$, entre os grupos pesquisados. Restle et $\mathrm{al}^{(15)}$ analisaram as características de carcaça dos machos castrados à faca ou com burdizzo e também não verificaram efeito entre os métodos de castração nos percentuais dos cortes primários da carcaça.

Já ao se comparar o efeito da castração no desenvolvimento dos animais em relação aos machos não castrados (Tabela 1), observa-se maior peso de dianteiro dos machos não castrados em relação aos animais castrados cirurgicamente $(\mathrm{P}<0,05)$, não havendo diferença desses para os castrados com burdizzo. Diferente do peso de traseiro especial, que não resultou em maior percentagem desse corte, o maior peso de dianteiro dos não castrados originou maior rendimento desse corte em relação aos três grupos de castração $(\mathrm{P}<0,05)$. Resultados similares que apontam para maior peso de cortes primários

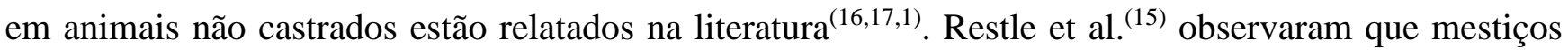
Charolês x Nelore castrados à faca ou com burdizzo foram inferiores aos não castrados no rendimento de dianteiro (38,2 contra 40,8\%), compensando com maiores percentuais de ponta de agulha (13,7 contra 12,9\%) e de traseiro especial (48,0 contra 46,2\%). Já em zebuínos Nelore, Clímaco et al. ${ }^{(18)}$ não observaram diferença nos percentuais e nos pesos dos cortes primários da carcaça entre os animais não castrados e os castrados aos treze meses de idade.

As diferenças no desenvolvimento de dianteiro dos animais não castrados é resultado do dimorfismo sexual decorrente dos efeitos anabólicos dos hormônios androgênicos e da alteração da ação gênica decorrente em resposta à castração ${ }^{(19)}$. Machos zebuínos não castrados mostram maior desenvolvimento 
de dianteiro relacionado ao dimorfismo sexual, conforme demonstrado por Restle et al. ${ }^{(20)}$ quando compararam mestiços 3/4 europeu $1 / 4$ zebu e 3/4 zebu 1/4 europeu. Também esses mesmos efeitos devem ter reduzido a precocidade de terminação dos animais o que se reflete em animais castrados com maior deposição de gordura, principalmente sobre as costelas e, consequentemente, maior rendimento de ponta-de-agulha nos animais castrados ${ }^{(2,21)}$, conforme apresentado na Tabela 1.

Observando-se os pesos (Tabela 2) e os rendimentos dos cortes do traseiro especial (Tabela 3), constatou-se efeito significativo dos grupos estudados apenas para peso e rendimento de lagarto, sendo maiores peso e rendimento desse corte observados em animais não castrados em relação aos demais, independente da forma de castração.

O lagarto é um corte que engloba o músculo semitendinosus mais o tecido adiposo adjacente. Não é de se esperar, nesse corte, variações de rendimento decorrentes de processos de desossa imprecisos, como pode acontecer na separação do coxão duro e da picanha, que são massas musculares contínuas ${ }^{(12)}$. O maior rendimento do lagarto nos animais não castrados pode ser indicativo da redução no desenvolvimento do semitendinosus com a castração, músculo considerado fundamental na articulação coxofemural, importante para o salto da cópula em reprodutores machos. Comparando machos não castrados e fêmeas bovinas, Costa et al. ${ }^{(22)}$ observaram que o lagarto foi o único corte desossado do traseiro especial que mostrou diferença entre os grupos sexuais.

A similaridade entre os pesos (Tabela 2) e rendimentos (Tabela 3) dos demais cortes do traseiro especial indica que a possível redução no crescimento advinda da castração pode estar compensada não só por maior deposição de gordura subcutânea ${ }^{(23)}$, mas também por deposição de gordura intermuscular. A sustentação dessa hipótese pode estar alicerçada na literatura que aponta para maior área de longissimus dorsi em animais não castrados ${ }^{(21)}$ e no estudo do peso e rendimento de contrafilé. Isso porque este corte é constituído basicamente pelo longissimus, a gordura subcutânea do lombo e os depósitos de gorduras intermusculares, na porção ventral do corte, preservadas na desossa, embora, algumas vezes, pouco representativas. 
Tabela 2: Médias e erros-padrão para pesos de cortes secundários do traseiro especial de mestiços de origem leiteira, não castrados ou submetidos a diferentes métodos de castração

\begin{tabular}{|c|c|c|c|c|}
\hline \multirow[b]{2}{*}{ Cortes } & \multicolumn{4}{|c|}{ Grupo analisado } \\
\hline & Não castrado & $\begin{array}{c}\text { Uso de } \\
\text { burdizzo }\end{array}$ & $\begin{array}{l}\text { Incisão } \\
\text { lateral }\end{array}$ & $\begin{array}{c}\text { Remoção do } \\
\text { tampão }\end{array}$ \\
\hline Traseiro especial, $\mathrm{kg}^{1}$ & $51,22 \pm 3,01$ & $47,72 \pm 2,97$ & $32,08 \pm 3,44$ & $32,82 \pm 3,43$ \\
\hline Coxão mole, kg & $7,25 \pm 0,24$ & $6,63 \pm 0,40$ & $6,60 \pm 0,43$ & $6,62 \pm 0,39$ \\
\hline Coxão duro, kg & $3,70 \pm 0,12$ & $3,40 \pm 0,20$ & $3,33 \pm 0,21$ & $3,59 \pm 0,19$ \\
\hline Patinho, kg & $4,24 \pm 0,11$ & $3,91 \pm 0,19$ & $3,82 \pm 0,20$ & $4,05 \pm 0,18$ \\
\hline Lagarto, kg & $2,06 \pm 0,07^{\mathrm{a}^{8}}$ & $1,73 \pm 0,12^{b}$ & $1,65 \pm 0,13^{b}$ & $1,72 \pm 0,12^{b}$ \\
\hline Contra filé, $\mathrm{kg}$ & $5,93 \pm 0,21$ & $5,09 \pm 0,35$ & $5,37 \pm 0,38$ & $5,18 \pm 0,34$ \\
\hline Filé mignon, $\mathrm{kg}$ & $1,43 \pm 0,09$ & $1,64 \pm 0,14$ & $1,37 \pm 0,15$ & $1,40 \pm 0,14$ \\
\hline Músculo, kg & $3,58 \pm 0,10$ & $3,40 \pm 0,17$ & $3,24 \pm 0,18$ & $3,40 \pm 0,16$ \\
\hline Miolo da alcatra, kg & $2,96 \pm 0,10$ & $2,60 \pm 0,17$ & $2,61 \pm 0,18$ & $2,84 \pm 0,16$ \\
\hline Picanha, kg & $1,03 \pm 0,05$ & $1,03 \pm 0,08$ & $0,96 \pm 0,09$ & $0,82 \pm 0,08$ \\
\hline Maminha, kg & $1,03 \pm 0,03$ & $0,95 \pm 0,06$ & $0,93 \pm 0,06$ & $0,99 \pm 0,05$ \\
\hline Fraldinha, kg & $0,88 \pm 0,04$ & $0,80 \pm 0,06$ & $0,85 \pm 0,07$ & $0,94 \pm 0,06$ \\
\hline Capa de filé, $\mathrm{kg}$ & $1,11 \pm 0,06$ & $0,98 \pm 0,11$ & $1,03 \pm 0,11$ & $0,95 \pm 0,10$ \\
\hline Bife da picanha, $\mathrm{kg}$ & $0,38 \pm 0,03$ & $0,33 \pm 0,05$ & $0,31 \pm 0,05$ & $0,27 \pm 0,05$ \\
\hline Total de cortes, $\mathrm{kg}$ & $35,56 \pm 1,06$ & $32,51 \pm 1,74$ & $32,08 \pm 1,86$ & $32,82 \pm 1,69$ \\
\hline Recorte de carne, kg & $2,59 \pm 0,11$ & $2,36 \pm 0,18$ & $2,13 \pm 0,20$ & $2,46 \pm 0,18$ \\
\hline Osso, kg & $11,05 \pm 0,34$ & $10,89 \pm 0,56$ & $10,20 \pm 0,60$ & $11,06 \pm 0,55$ \\
\hline Sebo, kg & $2,02 \pm 0,07$ & $1,96 \pm 0,04$ & $2,18 \pm 0,07$ & $1,86 \pm 0,08$ \\
\hline \multicolumn{5}{|c|}{$\begin{array}{l}{ }^{1} \text { Corte comercial que compreende a separação da ponta-de-agulha do traseiro total (também chamado de } \\
\text { traseiro capote) restando o traseiro especial, também conhecido como serrote. Compreende os subcortes } \\
\text { coxa e alcatrão. } \\
{ }^{*} \text { Médias na linha seguidas por letras diferentes diferem }(\mathrm{P}<0,05) \text { pelo Teste de Tukey. }\end{array}$} \\
\hline \multicolumn{5}{|c|}{$\begin{array}{l}\text { Tabela 3: Médias e erros-padrão para rendimentos de cortes secundários do traseiro } \\
\text { especial de mestiços de origem leiteira, não castrados ou submetidos a diferentes métodos } \\
\text { de castração }\end{array}$} \\
\hline \multirow[b]{2}{*}{ Cortes } & \multicolumn{4}{|c|}{ Grupo analisado } \\
\hline & Não castrado & $\begin{array}{c}\text { Uso de } \\
\text { burdizzo }\end{array}$ & $\begin{array}{l}\text { Incisão } \\
\text { lateral }\end{array}$ & $\begin{array}{l}\text { Remoção do } \\
\text { tampão }\end{array}$ \\
\hline Traseiro total, $\%$ & 48,4 & $49,03 \pm 0,33$ & $49,50 \pm 0,31$ & $49,40 \pm 0,44$ \\
\hline Coxão mole, \% & $14,30 \pm 0,30$ & $13,41 \pm 0,49$ & $13,54 \pm 0,52$ & $13,56 \pm 0,48$ \\
\hline Coxão duro, \% & $7,30 \pm 0,22$ & $6,89 \pm 0,37$ & $6,90 \pm 0,39$ & $7,40 \pm 0,36$ \\
\hline Patinho, \% & $8,35 \pm 0,16$ & $7,98 \pm 0,26$ & $7,92 \pm 0,28$ & $8,31 \pm 0,26$ \\
\hline Lagarto, \% & $4,06 \pm 0,10^{\mathrm{a}^{*}}$ & $3,48 \pm 0,16^{\mathrm{b}}$ & $3,43 \pm 0,17^{\mathrm{b}}$ & $3,54 \pm 0,16^{\mathrm{b}}$ \\
\hline Contra filé, $\%$ & $11,65 \pm 0,30$ & $10,33 \pm 0,49$ & $11,07 \pm 0,52$ & $10,67 \pm 0,48$ \\
\hline Filé mignon, \% & $2,81 \pm 0,23$ & $3,52 \pm 0,38$ & $2,83 \pm 0,40$ & $2,86 \pm 0,37$ \\
\hline Músculo, \% & $7,04 \pm 0,13$ & $6,91 \pm 0,21$ & $6,73 \pm 0,22$ & $6,99 \pm 0,20$ \\
\hline Miolo da alcatra, \% & $5,83 \pm 0,15$ & $5,28 \pm 0,24$ & $5,39 \pm 0,26$ & $5,83 \pm 0,24$ \\
\hline Picanha, \% & $2,04 \pm 0,08$ & $2,06 \pm 0,14$ & $1,99 \pm 0,15$ & $1,81 \pm 0,14$ \\
\hline Maminha, \% & $2,02 \pm 0,05$ & $1,92 \pm 0,09$ & $1,92 \pm 0,09$ & $2,03 \pm 0,08$ \\
\hline Fraldinha, \% & $1,72 \pm 0,07$ & $1,65 \pm 0,11$ & $1,75 \pm 0,12$ & $1,94 \pm 0,11$ \\
\hline Capa de filé, \% & $2,19 \pm 0,12$ & $1,95 \pm 0,19$ & $2,11 \pm 0,20$ & $1,95 \pm 0,18$ \\
\hline Bife da picanha, $\%$ & $0,73 \pm 0,05$ & $0,66 \pm 0,08$ & $0,64 \pm 0,08$ & $0,54 \pm 0,08$ \\
\hline Recorte, \% & $5,15 \pm 0,21$ & $4,72 \pm 0,34$ & $4,39 \pm 0,37$ & $5,01 \pm 0,33$ \\
\hline Osso, $\%$ & $21,78 \pm 0,51$ & $22,25 \pm 0,84$ & $21,00 \pm 0,90$ & $22,64 \pm 0,82$ \\
\hline Sebo, $\%$ & $3,97 \pm 0,17$ & $4,01 \pm 0,29$ & $4,54 \pm 0,31$ & $3,78 \pm 0,28$ \\
\hline
\end{tabular}

* Médias na linha seguidas por letras diferentes diferem $(\mathrm{P}<0,05)$ pelo Teste de Tukey. 
Estudando apenas dois cortes desossados, Vieira e Silva et al. ${ }^{(23)}$ verificaram que o maior peso do contrafilé pode ser explicado por um possível maior comprimento de carcaça dos animais não castrados, efeito que não se refletiu na desossa da picanha, corte que possui participação de gordura subcutânea.

No estudo dos cortes do dianteiro (Tabela 4), observou-se que o peso do acém foi maior nos animais não castrados em relação aos animais castrados, o que reflete o maior dimorfismo sexual dos não castrados, já discutido anteriormente, no qual os machos desenvolvem a musculatura dianteira mais pronunciada $^{(17,22)}$.

Não houve diferença estatística entre os quatro grupos pesquisados em relação aos pesos (Tabela 4) e aos percentuais (Tabela 5) de subprodutos recorte, ossos e sebo. O fato de boa parte da literatura apontar para maior musculosidade e menor acabamento de carcaça em animais não castrados ${ }^{(3,24)}$ poderia indicar menor percentual de sebo nas carcaças dos animais não castrados, o que talvez não tenha ocorrido em função dos animais serem oriundos de cruzamento com raça leiteira, limitando as deposições de gordura corporal, diferente do que ocorreu em trabalhos que usaram animais terminados com concentrados de altas densidades energéticas ${ }^{(1,7,17,21,23)}$.

Em sua pesquisa, Rodriguez et al. ${ }^{(24)}$ não observaram diferenças no percentual de carne comercializável entre bovinos não castrados e castrados em diferentes idades, mas observaram que o descarte de ossos e gordura de toalete foi maior nos animais não castrados $(24,2 \%)$ em relação aos novilhos castrados aos três $(22,2 \%)$ ou sete meses de idade $(21,9 \%)$. Marti et al. ${ }^{(7)}$ relatam que, embora os animais não castrados apresentassem maior percentual de ossos, estes mostraram maior rendimento de carne magra desossada, pois os animais castrados aos três ou oito meses de idade apresentaram percentual de gordura separável mais expressiva do que os bovinos não castrados.

Tabela 4: Médias e erros-padrão para os pesos dos cortes secundários do dianteiro de mestiços de origem leiteira, não castrados ou submetidos a diferentes métodos de castração

\begin{tabular}{lcccc}
\hline \multirow{2}{*}{ Cortes } & \multicolumn{4}{c}{ Grupo analisado } \\
\cline { 2 - 5 } & Não castrado & $\begin{array}{c}\text { Uso de } \\
\text { burdizzo }\end{array}$ & Incisão lateral & $\begin{array}{c}\text { Remoção do } \\
\text { tampão }\end{array}$ \\
\hline Dianteiro, kg & $42,81 \pm 1,74$ & $37,26 \pm 2,85$ & $36,24 \pm 3,05$ & $38,35 \pm 2,77$ \\
Acém, kg & $13,74 \pm 0,63^{\mathrm{a}^{*}}$ & $10,82 \pm 1,03^{\mathrm{b}}$ & $10,34 \pm 1,11^{\mathrm{b}}$ & $11,32 \pm 1,01^{\mathrm{b}}$ \\
Paleta, kg & $8,63 \pm 0,48$ & $7,86 \pm 0,78$ & $7,74 \pm 0,84$ & $8,16 \pm 0,76$ \\
Peito, kg & $4,28 \pm 0,17$ & $3,88 \pm 0,28$ & $3,88 \pm 0,30$ & $3,89 \pm 0,27$ \\
Músculo, kg & $2,95 \pm 0,16$ & $3,04 \pm 0,26$ & $2,86 \pm 0,28$ & $2,98 \pm 0,25$ \\
Tendinoso, kg & $0,25 \pm 0,03$ & $0,06 \pm 0,05$ & $0,10 \pm 0,05$ & $0,07 \pm 0,05$ \\
Total de cortes, kg & $29,85 \pm 1,12^{\mathrm{a}}$ & $25,66 \pm 1,85^{\mathrm{b}}$ & $24,92 \pm 1,98^{\mathrm{b}}$ & $26,42 \pm 1,80^{\mathrm{ab}}$ \\
Recorte, kg & $0,94 \pm 0,08$ & $0,75 \pm 0,13$ & $0,94 \pm 0,14$ & $0,73 \pm 0,12$ \\
Osso, kg & $10,03 \pm 0,29$ & $9,45 \pm 0,48$ & $9,11 \pm 0,51$ & $9,88 \pm 0,46$ \\
Sebo, kg & $1,99 \pm 0,11$ & $1,40 \pm 0,18$ & $1,27 \pm 0,20$ & $1,32 \pm 0,18$ \\
\hline
\end{tabular}

* Médias na linha seguidas por letras diferentes diferem $(\mathrm{P}<0,05)$ pelo Teste de Tukey. 
Tabela 5: Médias e erros-padrão para os rendimentos dos cortes secundários do dianteiro de mestiços de origem leiteira, não castrados ou submetidos a diferentes métodos de castração

\begin{tabular}{lcccc}
\hline \multirow{2}{*}{ Cortes } & \multicolumn{4}{c}{ Grupo analisado } \\
\cline { 2 - 5 } & Não castrados & $\begin{array}{c}\text { Uso de } \\
\text { burdizzo }\end{array}$ & Incisão lateral & $\begin{array}{c}\text { Remoção do } \\
\text { tampão }\end{array}$ \\
\hline Acém, \% & $32,72 \pm 1,19^{\mathrm{a}^{*}}$ & $27,60 \pm 1,96^{\mathrm{b}}$ & $27,78 \pm 2,10^{\mathrm{b}}$ & $28,90 \pm 1,91^{\mathrm{ab}}$ \\
Paleta, \% & $20,75 \pm 1,09$ & $20,25 \pm 1,79$ & $20,94 \pm 1,92$ & $20,90 \pm 1,75$ \\
Peito, \% & $10,19 \pm 0,26$ & $9,87 \pm 0,42$ & $10,47 \pm 0,45$ & $10,02 \pm 0,41$ \\
Músculo, \% & $7,11 \pm 0,39$ & $7,83 \pm 0,64$ & $7,84 \pm 0,69$ & $7,62 \pm 0,63$ \\
Tendinoso, \% & $0,59 \pm 0,15$ & $0,15 \pm 0,24$ & $0,29 \pm 0,26$ & $0,18 \pm 0,23$ \\
Recorte, \% & $2,24 \pm 0,18$ & $1,94 \pm 0,29$ & $2,48 \pm 0,32$ & $1,91 \pm 0,29$ \\
Osso, \% & $23,95 \pm 0,62$ & $24,48 \pm 1,02$ & $24,83 \pm 1,09$ & $25,39 \pm 1,00$ \\
Sebo, \% & $4,36 \pm 0,22$ & $3,56 \pm 0,36$ & $3,47 \pm 0,38$ & $3,34 \pm 0,35$ \\
\hline
\end{tabular}

* Médias na linha seguidas por letras diferentes diferem $(\mathrm{P}<0,05)$ pelo Teste de Tukey.

A Tabela 5 mostra que o maior peso de acém relatado na Tabela 4 refletiu-se também em maior rendimento desse corte em relação ao peso de carcaça nos animais não castrados comparados aos castrados com burdizzo ou por incisão lateral. O maior percentual desse corte, no presente trabalho, reflete o maior desenvolvimento de dianteiro dos animais não castrados (Tabela 1), já que esse corte representa a peça de maior proporção no dianteiro e o presente estudo não realizou a separação entre os cortes acém e pescoço, encontrada em outros trabalhos ${ }^{(12)}$.

Analisando a receita com a venda dos cortes primários (Tabela 6), observou-se que esta foi maior nos animais não castrados em relação aos demais. Entretanto, o fato de os animais castrados apresentarem melhor rendimento de traseiro especial, corte mais valorizado pelo atacado e pelo varejo, o preço de equilíbrio foi favorável a estes, principalmente os castrados cirurgicamente, em relação aos animais não castrados, observando-se nos bovinos castrados com burdizzo um valor intermediário. O preço de equilíbrio mostra o preço que a indústria frigorífica poderia pagar pela arroba de carcaça, para obter lucro zero, considerando como custo apenas o preço de aquisição de matéria prima carcaça, bem como os cortes primários como única fonte de receita da mesma indústria.

Considerando a desossa dos cortes primários em cortes secundários, a Tabela 7 mostra que a diferença relativa de receita dos animais castrados em relação aos mantidos não castrados foi 0,927; 0,901 e 0,911, respectivamente para castrados com burdizzo, castrados por incisão lateral e castrados com remoção do tampão. 
Tabela 6: Receitas com a venda dos cortes primários da carcaça de mestiços de origem leiteira, não castrados ou submetidos a diferentes métodos de castração

\begin{tabular}{lrrrr}
\hline & \multicolumn{4}{c}{ Grupo analisado } \\
\cline { 2 - 5 } Características & \multicolumn{1}{c}{$\begin{array}{c}\text { Não } \\
\text { castrados }\end{array}$} & $\begin{array}{c}\text { Uso de } \\
\text { burdizzo }\end{array}$ & $\begin{array}{c}\text { Incisão } \\
\text { lateral }\end{array}$ & $\begin{array}{r}\text { Remoção } \\
\text { do tampão }\end{array}$ \\
\hline Traseiro especial, R\$ & 848,38 & 817,96 & 826,41 & 748,67 \\
Dianteiro, R\$ & 453,44 & 412,57 & 407,12 & 373,33 \\
Ponta de agulha, R\$ & 124,44 & 131,58 & 130,05 & 115,26 \\
Receita cortes primários, $\mathrm{R} \$$ & $1.426,26$ & $1.362,11$ & $1.363,58$ & $1.237,26$ \\
Diferença relativa (não & & & & \\
castrados) & 1,000 & 0,955 & 0,956 & 0,867 \\
Preço de equilíbrio, $\mathrm{R} \$$ @ $^{3}$ & 102,83 & 103,03 & 103,30 & 103,28 \\
\hline
\end{tabular}

${ }_{1}^{1}$ Preços baseados no Boletim Intercarnes número 4.828, de 17 de setembro de 2013, autorizado por Intercarnes Intermediação e Comércio Ltda. ${ }^{2}$ Calculado como: receita do grupo castrado / receita do grupo não castrados. ${ }^{3}$ Calculado pela divisão da receita da venda dos cortes pelo número de arrobas das carcaças (Tabela 1).

A maior receita dos não castrados em relação aos castrados foi devido, não tanto por diferenças de receitas relativas altas dos não castrados em relação à média dos castrados, como no corte lagarto (21\% maior), no bife da picanha ( $25 \%$ maior) ou no músculo tendinoso (227\% maior), mas principalmente pela representatividade da receita de cortes com pesos expressivos. Exemplo disso são as receitas $\mathrm{R} \$$ 6,71 maior com coxão mole, $\mathrm{R} \$$ 8,60 maior com contrafilé, $\mathrm{R} \$$ 6,23 maior com paleta e $\mathrm{R} \$ 20,68$ maior com acém. Por outro lado, as receitas maiores na média dos castrados foram bem menos expressivas, como $\mathrm{R}$ \$ 0,08 no músculo do traseiro, $\mathrm{R} \$ 0,76$ no filé mignon e $\mathrm{R} \$ 1,26$ na ponta de agulha.

Maiores receitas com paleta e acém são reflexos do maior percentual de dianteiro dos animais não castrados já discutido na Tabela 1, enquanto as maiores receitas do coxão mole e do contrafilé podem ser resultado de melhor conformação dos animais não castrados, expressa nos perfis musculares e adiposos da carcaça, resultando em maior peso de coxão mole e pela maior área de longissimus dorsi $^{(7,25,26)}$, resultando em contrafilé mais pesado.

Em relação aos valores de preço de equilíbrio com a receita de cortes desossados, observa-se na Tabela 7 que este foi mais alto e, portando, mais favorável nos animais castrados com a remoção do tampão ( $\mathrm{R}$ \$121,00/@), seguidos dos animais não castrados ( $\mathrm{R} \$ 114,69 / @)$, dos castrados com burdizzo (R\$ 111,49/@), enquanto os castrados por incisão lateral tiveram o preço de equilíbrio mais baixo ( $\mathrm{R} \$$ 109,40/@).

Os resultados do presente trabalho mostram que estudos que aliam os rendimentos dos cortes primários ou secundários da carcaça com os preços de venda na indústria frigorífica podem representar análises melhor ajustadas da viabilidade das cadeias de produção, trazendo novas discussões aos produtores rurais e aos dirigentes de agroindústrias. Isso porque as pesquisas em produção animal e carcaças até então apontaram para os rendimentos dos cortes, desconsiderando as diferenças de valor industrial entre estes.

Pesquisadores australianos constataram que as pesquisas de hoje precisam produzir resultados para a indústria e para os consumidores, baseadas em trabalhos cooperativos envolvendo a indústria, a ciência 
e a genética de forma simultânea ${ }^{(27)}$. Para os mesmos autores, tais abordagens requerem investimentos subjacentes que combinem indústria e financiamentos do estado.

Tabela 7: Receitas (em R\$) com a venda dos cortes secundários desossados de mestiços de origem leiteira, não castrados ou submetidos a diferentes métodos de castração

\begin{tabular}{|c|c|c|c|c|c|}
\hline \multirow[t]{2}{*}{ Corte desossado } & \multicolumn{5}{|c|}{ Receitas baseadas no preço médio de mercado $^{1}$} \\
\hline & $\mathbf{R} \mathbf{s g}$ & $\begin{array}{c}\text { Não } \\
\text { castrados }\end{array}$ & $\begin{array}{c}\text { Uso de } \\
\text { burdizzo }\end{array}$ & $\begin{array}{l}\text { Incisão } \\
\text { lateral }\end{array}$ & $\begin{array}{c}\text { Remoção do } \\
\text { tampão }\end{array}$ \\
\hline Coxão mole & 10,60 & 76,85 & 70,28 & 69,96 & 70,17 \\
\hline Coxão duro & 9,50 & 35,15 & 32,30 & 31,64 & 34,11 \\
\hline Patinho & 10,30 & 43,67 & 40,27 & 39,35 & 41,72 \\
\hline Lagarto & 9,50 & 19,57 & 16,44 & 15,68 & 16,34 \\
\hline Contra filé & 12,00 & 71,16 & 61,08 & 64,44 & 62,16 \\
\hline Filé mignon & 19,00 & 27,17 & 31,16 & 26,03 & 26,60 \\
\hline Músculo traseiro & 8,30 & 29,71 & 28,22 & 26,89 & 28,22 \\
\hline Miolo da alcatra & 12,60 & 37,30 & 32,76 & 32,89 & 35,78 \\
\hline Picanha & 22,00 & 22,66 & 22,66 & 21,12 & 18,04 \\
\hline Maminha & 12,80 & 13,18 & 12,16 & 11,90 & 12,67 \\
\hline Fraldinha & 9,00 & 7,92 & 7,20 & 7,65 & 8,46 \\
\hline Capa de filé & 7,20 & 7,99 & 7,06 & 7,42 & 6,84 \\
\hline Bife da picanha & 12,60 & 4,79 & 4,16 & 3,91 & 3,40 \\
\hline Acém & 7,10 & 97,55 & 76,82 & 73,41 & 80,37 \\
\hline Paleta & 8,77 & 75,69 & 68,93 & 67,88 & 71,56 \\
\hline Peito & 6,70 & 28,68 & 26,00 & 26,00 & 26,06 \\
\hline Músculo & 8,30 & 24,49 & 25,23 & 23,74 & 24,73 \\
\hline Tendinoso & 8,30 & 2,08 & 0,50 & 0,83 & 0,58 \\
\hline Ponta de agulha ${ }^{2}$ & 5,40 & 131,76 & 139,32 & 137,70 & 122,04 \\
\hline Recorte magro & 4,00 & 14,12 & 12,44 & 12,28 & 12,76 \\
\hline Sebo & 1,70 & 6,82 & 5,71 & 5,87 & 5,41 \\
\hline Osso & 0,80 & 16,86 & 16,27 & 15,45 & 16,75 \\
\hline Total $1 / 2$ carcaça & & 795,17 & 736,96 & 722,01 & 724,78 \\
\hline Total carcaça inteira ${ }^{3}$ & & $1.590,34$ & $1.473,93$ & $1.444,02$ & $1.449,56$ \\
\hline Dif. relativa (não castrados) ${ }^{4}$ & & 1,000 & 0,927 & 0,901 & 0,911 \\
\hline Preço de equilibrio, $R \$ / @,^{5}$ & & 114,69 & 111,49 & 109,40 & 121,00 \\
\hline
\end{tabular}

${ }^{1}$ Preços baseados no Boletim Intercarnes número 4.828 , de 17 de setembro de 2013 , autorizado por Intercarnes Intermediação e Comércio Ltda. ${ }^{2}$ Corte primário sem fraldinha. ${ }^{3}$ Calculado pela multiplicação do valor da $1 / 2$ carcaça por $2 .{ }^{4}$ Calculado como: receita do grupo castrado / receita do grupo não castrados. ${ }^{5}$ Calculado pela divisão da receita da venda dos cortes pelo número de arrobas das carcaças (Tabela 1). 


\section{Conclusões}

Recomenda-se a castração de animais mestiços leiteiros em função do aumento do rendimento de ponta-de-agulha, pois a desossa de cortes secundários do traseiro especial é similar entre animais inteiros e castrados.

Animais castrados cirurgicamente apresentaram na comercialização de cortes primários preço de equilíbrio mais favorável. $\mathrm{Na}$ venda de cortes secundários, maiores pesos de coxão mole, contrafilé e acém favoreceram em 8,7\% os animais não castrados.

\section{Referências}

1. Jones SDM, Burgess TD, Wilton JW, Watson CH. Feedlot performance, carcass composition and eficiency of muscle gain in bulls and steers of different mature size slaughtered at similar levels of fatness. Can J Anim Sci. 1984;64(2):621-30.

2. Euclides Filho K, Feijó GLD, Figueiredo GR, Euclides VPB, Silva LOC, Cusinato VQ. Efeito de idade à castração e de grupos genéticos sobre o desempenho em confinamento e características de carcaça. Rev Bras Zootec. 2001;30(1):71-6. Portuguese.

3. Monteiro CG, Navas D, Lemos JPC. Efeito da castração e da idade nas características da carne de bovinos produzidos em sistema de pastoreio. Rev Portug Zootec. 2005;12(2):77-90. Portuguese.

4. Vittori A, Gesualdi Júnior A, Queiroz AC, Resende FD, Alleoni GF, Razook AG et al. Desempenho produtivo de bovinos de diferentes grupos raciais, castrados e não-castrados, em fase de terminação. Arq Bras Med Vet Zootec. 2007;59(5):1263-9. Portuguese.

5. Ítavo LCV, Dias AM, Ítavo CCBF, Euclides Filho K, Morais MG, Silva FF et al. Desempenho produtivo, características de carcaça e avaliação econômica de bovinos cruzados, castrados e não-castrados, terminados em pastagens de Brachiaria decumbens. Arq Bras Med Vet e Zootec. 2008;60(5):1157-1165. Portuguese.

6. Pinheiro RMK, Silva TJP, Viana JHM. Influência do grupo genético, condição sexual e tratamento antiparasitário nas medidas de área de olho do lombo e espessura de gordura in vivo e na carcaça de bovinos de corte. Arq Bras Med Vet Zootec. 2009;61(3):676-81. Portuguese.

7. Martí S, Realini CE, Bach A, Pérez-Juan M, Devant M. Effect of castration and slaughter age on performance, carcass, and meat quality traits of Holstein calves fed a high-concentrate diet. J Anim Sci. 2013;91(3):1129-40.

8. Lopes MA, Santos G, Rosa LV, Lopes NM. Rentabilidade da terminação em confinamento de bovinos de corte castrados e não castrados. Bol Ind Anim. 2005;62(4):289-94. Portuguese.

9. Mach N, Bach A, Realini CE, Font I, Furnols M, Velarde A et al. Burdizzo pre-pubertal castration effects on performance, behaviour, carcass characteristics, and meat quality of Holstein bulls fed high-concentrate diets. Meat Sci. 2009;81(2):329-34.

10. Marti S, Velarde A, Torre JL, Bach A, Aris A, Serrano A, Manteca X, Devant M. Effects of ring castration with local anesthesia and analgesia in holstein calves at 3 months of age on welfare indicators. J Anim Sci. 2010;88(4):2789-96.

Cienc. anim. bras., v.16, n.1, p. 54-67, jan./mar. 2015 
11. Pádua JT, Oliveira MP, Silva LAF, Vieira LS, Figuerêdo EJ, Morales DCSP, Carrijo LHD, Martins AFC. Efeito de métodos de castração e do uso de vermífugos sobre o ganho em peso de bovinos mestiços leiteiros. Ci Anim Bras. 2003;4(1):33-43. Portuguese.

12. Pascoal LL, Lobato JFP, Restle J, Vaz FN, Vaz RZ, Menezes LFG. Beef cuts yield of steer carcasses graded according to conformation and weight. Rev Bras Zootec. 2010;39(6):1363-71.

13. Restle J, Grassi C, Feijó GLD. Desenvolvimento e rendimento de carcaça de bovinos inteiros ou submetidos a duas formas de castração, em condições de pastagem. Rev Bras Zootec. 1996b;25(2):323-33. Portuguese.

14. Silva LAF, Costa AC, Soares LK, Borges NC, Ferreira JL, Cardoso LA. Orquiectomia em bovinos empregando abraçadeira de náilon na hemostasia preventiva: efeito da estação do ano, método de contenção e técnica cirúrgica. Ci Anim Bras. 2009;10(1):261-70. Portuguese.

15. Restle J, Grassi C, Feijó GLD. Características das carcaças e da carne de bovinos inteiros ou submetidos a duas formas de castração Rev Bras Zootec.1996a;25(2):334-44. Portuguese.

16. Rodrigues VC, Andrade IF, Freitas RT, Bressan MC, Teixeira JC. Rendimentos do abate e carcaça de bovinos e bubalinos castrados e inteiros. Rev Bras Zootec. 2003;32(3):663-71. Portuguese.

17. Freitas AK, Restle J, Pacheco PS, Pádua JT, Lage ME, Miyagi ES et al. Características de carcaças de bovinos Nelore inteiros $v s$ castrados em duas idades, terminados em confinamento. Rev Bras Zootec. 2008;37(6):1055-62. Portuguese.

18. Climaco SM, Ribeiro ELA, Mizubuti IY, Rocha MA da, Silva LDF da, Pereira ES. Desempenho e características de carcaça de bovinos de corte inteiros ou castrados e suplementados ou não durante o inverno. Acta Scient Anim Sci. 2006;28(2):209-214. Portuguese.

19. Zhou ZK, Gao X, Li JY, Chen JB, Xu SZ. Effect of castration on carcass quality and differential gene expression of longissimus muscle between steer and bull. Molec Biol Rep. 2011;38(8):5307-12.

20. Restle J, Vaz FN, Feijó GLD, Brondani IL, Alves Filho DC, Bernardes RALC et al. Características de carcaça de bovinos de corte inteiros ou castrados de diferentes composições raciais Charolês x Nelore. Rev Bras Zootec. 2000;29(5):1371-9. Portuguese.

21. Kuss F, López J, Barcellos JOJ, Restle J, Moletta JL, Perotto D. Características da carcaça de novilhos nãocastrados ou castrados terminados em confinamento e abatidos aos 16 ou 26 meses de idade Rev Bras Zootec. 2009;38(3):515-22. Portuguese.

22. Costa DPB, Mourão RC, Moustaca, VS, Abreu JBR, Sousa JCD, Vieira AO. Rendimento dos cortes comerciais da carcaça de vacas de descarte e de novilhos inteiros Nelore, terminados em Brachiaria decumbens. Agrop Cient Semi-Árido. 2010;6(1):14-8. Portuguese.

23. Vieira e Silva F, Rocha Júnior VR, Barros RC, Pires DAA, Menezes GCC, Caldeira LA. Ganho de peso e características de carcaça de bovinos Nelore castrados ou não-castrados terminados em confinamento Rev Bras Zootec. 2008;37(12):2199-205. Portuguese.

24. Rodriguez J, Unruh J, Villareal M, Murillo O, Rojas S, Camacho J et al. Carcass and meat quality characteristics of Brahman cross bulls and steers finished on tropical pastures in Costa Rica. Meat Sci. 2014;96(3):1340-4. 
25. Vaz FN, Restle J, Feijó GLD, Brondani IL, Rosa JRP, Santos AP. Qualidade e composição química da carne de bovinos de corte inteiros ou castrados de diferentes grupos genéticos Charolês x Nelore. Rev Bras Zootec. 2001;30(2):518-25. Portuguese.

26. Amatayakul-Chantler S, Hoe F, Jackson JA, Roca RO, Stegner LE, King V. Effects on performance and carcass and meat quality attributes following immunocastration with the gonadotropin releasing factor vaccine Bopriva or surgical castration of Bos indicus bulls raised on pasture in Brazil. Meat Sci. 2013;95(1):78-84.

27. Pethick DW, Ball AJ, Banks RG, Hocquette JF. Current and future issues facing red meat quality in a competitive market and how to manage continuous improvement. Anim Prod Sci. 2011;51(1):13-8. 